\title{
CUBIERTAS TIPO ESTRUCTURAL ESPACIAL DE BAJO COSTE ${ }^{*}$ )
}

886-38

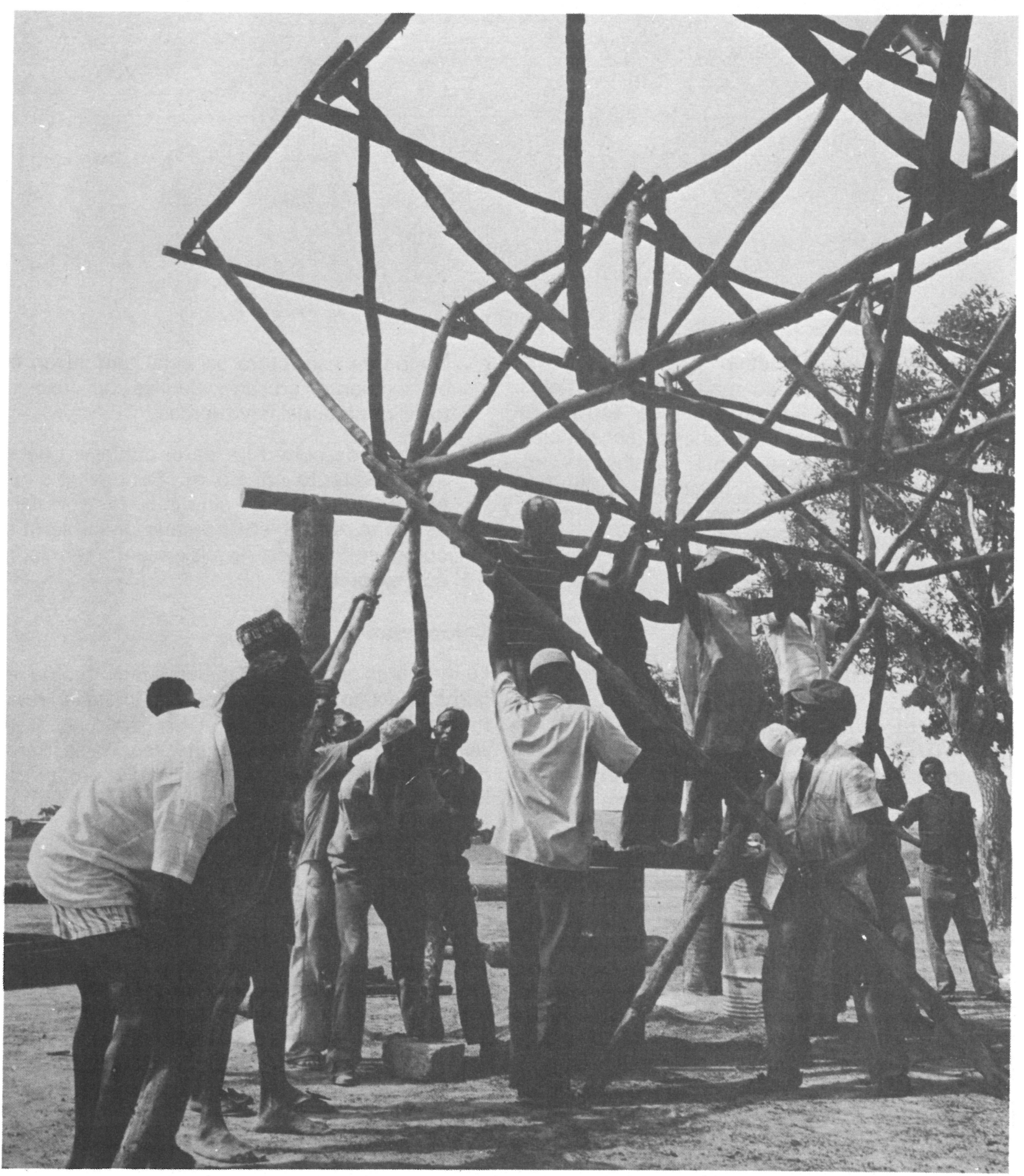

(") El texto y gráficos de este trabajo han sido tomados de la información técnica de la empresa sueca HABITROPIC, que explota la patente descrita. 


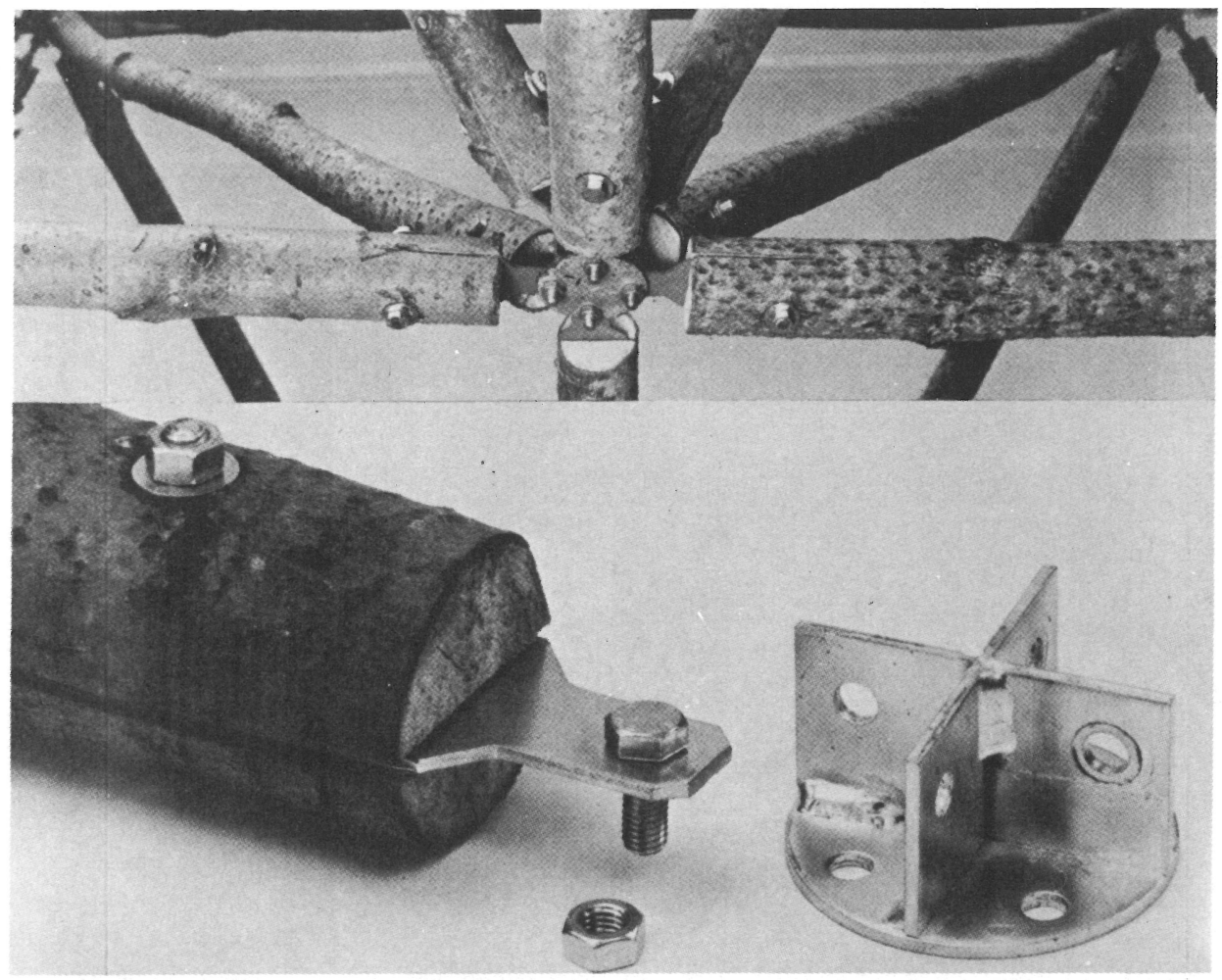

Habitropic lanza un nuevo componente que permite la colocación de maderos no tratados para la realización de cubiertas de estructura espacial. Este nuevo componente se concibe especialmente para las zonas rurales de los países del Tercer Mundo, haciendo posible de esta forma una utilización máxima de la mano de obra y de los materiales locales.

\section{Descripción técnica}

La presente estructura espacial consiste en:

1. Madera de monte de dimensiones 1,5 $\mathrm{m} \times$ $\times 5-6 \mathrm{~cm}$. Los elementos considerados no necesitan ser absolutamente rectilíneos. También es posible utilizar madera serrada a escuadra. Como resultado de los claros, que se dejan en las repoblaciones forestales, esta madera es aprovechable como maderos.
2. Nudos de estructura espacial que llevan en un elemento cruzado patillas de fijación, tornillos, arandelas y tuercas.

3. Material de cobertura de la cubierta que es autorresistente en 1,5 m. Por ejemplo: de chapa ondulada, de aluminio, de hormigón de fibras, etc. Si es necesario, la cubierta se complementa con un aislamiento térmico o con un techo.

\section{Colocación}

La preparación de los maderos se efectúa en grandes series. Valdría para ello un taller rural. Primeramente los maderos se perforan y se sierran con plantilla. Si es necesario, se tratan químicamente a continuación o se dotan con otros medios de protección contra los insectos. Después, se colocan las patillas de fijación y se juntan los maderos en lotes con objeto de transportarlos a la obra.

\begin{tabular}{|c|c|c|c|}
\hline Especificaciones & & $\begin{array}{l}\text { - Consumo de materiales por } \\
\mathrm{m}^{2} \text { : }\end{array}$ & $\begin{array}{l}\text { Aprox. } 3,5 \text { maderos. } \\
\text { Aprox. } 1,1 \text { nudo de estructura } \\
\text { espacial. }\end{array}$ \\
\hline $\begin{array}{l}\text { - Forma geométrica de los } \\
\text { elementos: }\end{array}$ & $1 / 2$ octaedros $y$ tetraedros. & - Peso: & $\begin{array}{l}\text { Aprox. } 20 \mathrm{~kg} / \mathrm{m}^{2} \text { de superficie } \\
\text { construida. }\end{array}$ \\
\hline - Longitud de los maderos: & 1,5 metros. & & \\
\hline - Luz máxima: & $\begin{array}{l}15 \text { metros con apoyos con- } \\
\text { tinuos laterales. }\end{array}$ & $\begin{array}{l}\text { - Carga máxima por ma- } \\
\text { dero: }\end{array}$ & $\begin{array}{l}10 \mathrm{kN}(1000 \mathrm{kp}) \text {, siendo la } \\
\text { presión ejercida por el vien- } \\
\text { to de } \pm 1 \mathrm{kPa}\left(100 \mathrm{kp} / \mathrm{m}^{2}\right) \text {. }\end{array}$ \\
\hline
\end{tabular}



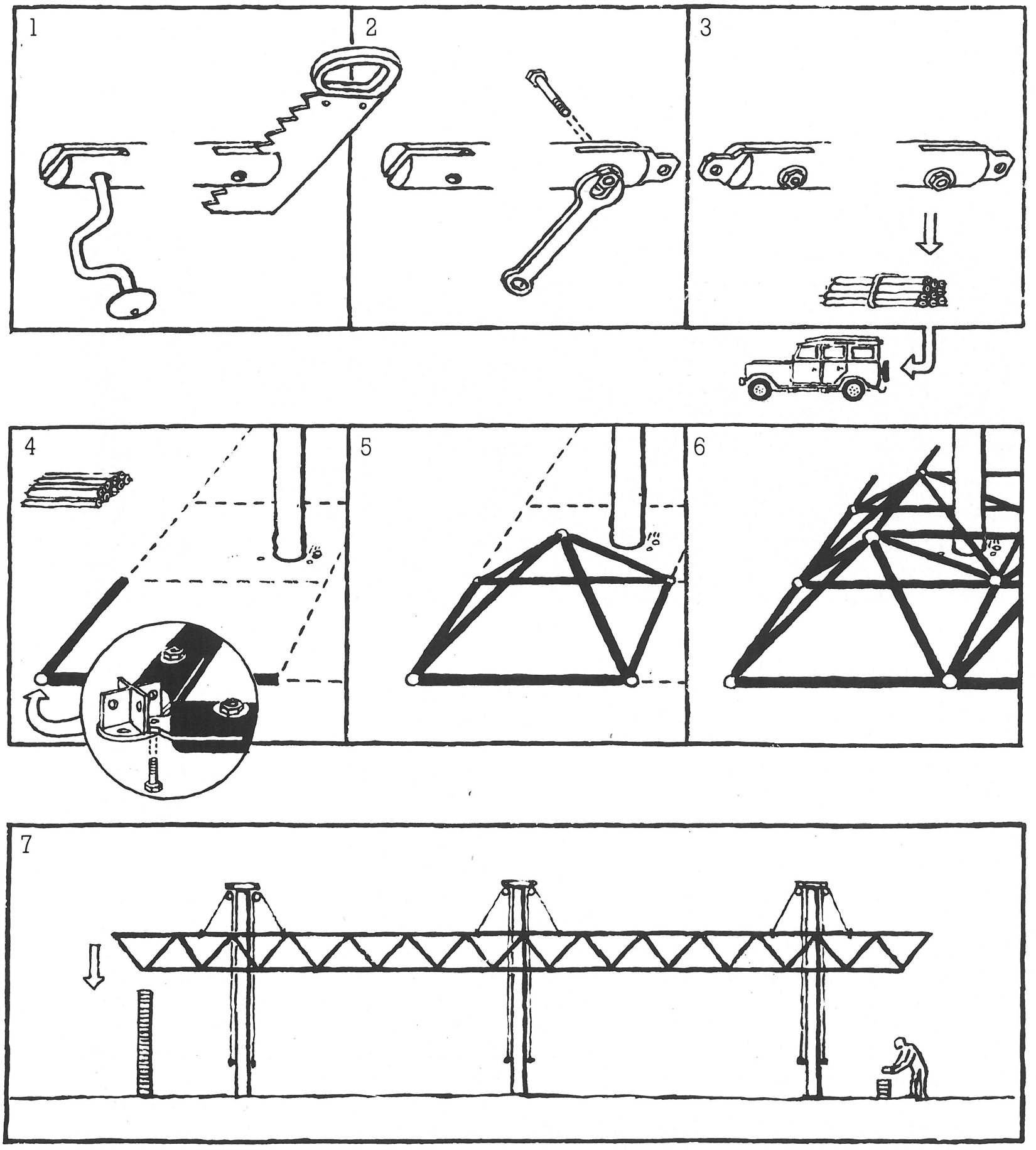

La ensambladura de la cubierta de estructura espacial se realiza en el suelo. Primero los maderos se disponen como si formaran un tablero de ajedrez.

A continuación se fija cada madero mediante un elemento cruzado. A partir de cada cuadrado se levantan pirámides de cuatro caras, reuniendo el mismo tipo de elemento cruzado los cuatro maderos en la cúspide. Finalmente, se coloca y se une a los elementos cruzados por las cúspides una red superior de maderos.
Ahora puede levantarse la cubierta de estructura espacial. Incluso si su peso por $\mathrm{m}^{2}$ es pequeño $(20 \mathrm{~kg})$, la estructura resulta pesada debido a sus dimensiones. Para evitar cualquier accidente, la elevación de la estructura requiere el uso de soportes y poleas. Conviene cualquier ubicación de los soportes dentro de los límites de la red, efectuándose preferentemente la colocación antes de la erección de las pirámides. Colocar las poleas en la cúspide de cada soporte para elevar la estructura espacial ligeramente por encima de la altura definitiva. Después de le- 


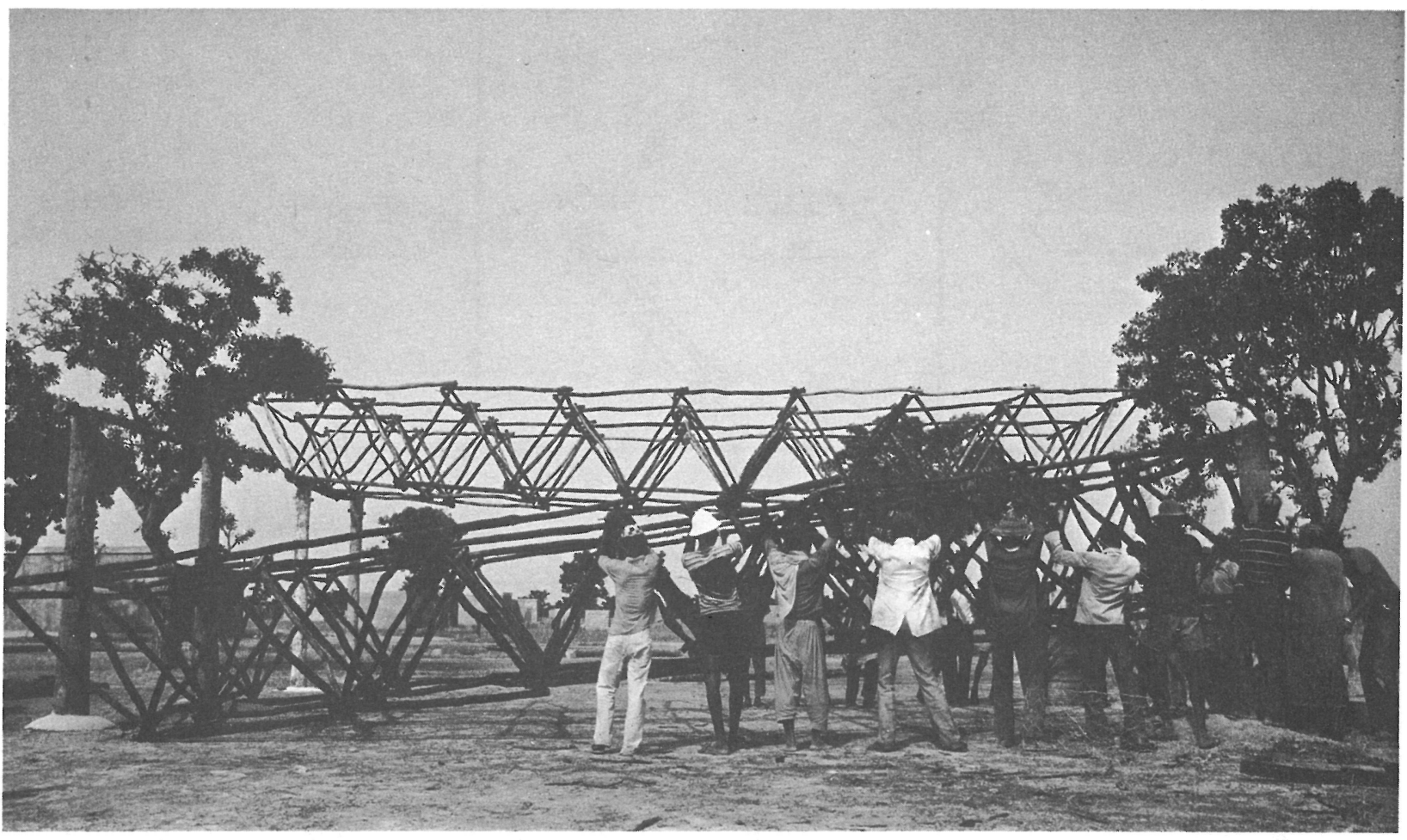

vantarse la estructura, se desarrolla la construcción de los muros, soportes de carga y vigas necesarias. Tras realizarse los apoyos para la cubierta, la estructura espacial se baja hasta colocarse en su altura definitiva.

\section{Generalidades}

Cualquiera que sea la aplicación considerada (salas de reunión, talleres, hangares, etc.), siempre es difícil construir la cubierta de edificios de grandes vanos. Sin embargo, las sociedades tradicionales no conocen este tipo de problemas, ya que no sienten la necesidad de tener edificios con una amplia cubierta.

A la par con los esfuerzos de desarrollo, estas sociedades tradicionales sufren un alza rápida de la demanda para este tipo de obra. Así los alumnos tienen que ver, al mismo tiempo, al maestro y el encerado; los espectadores tienen que asistir a la proyección de películas; los camiones tienen que entrar en los almacenes $y$ salir de ellos; los aviones necesitan hangares, etcétera. En estos casos, las estructuras metá- licas suelen ser importadas y ensambladas por soldadura de cerchas. Además, las regiones forestales han empleado las más avanzadas estructuras espaciales. Se han aceptado costes elevados con el fin de conseguir la actividad deseada, alcanzando sin embargo sus precios, en ciertos casos, del 25 al $30 \%$ de los gastos totales de construcción.

La idea de resolver el problema utilizando los materiales locales se remonta a la construcción de una escuela, en el Alto Volta, donde son escasos los grandes árboles. Si fuera posible concebir una cubierta de estructura espacial, sería posible utilizar madera de monte, de pocas dimensiones. Algunas experiencias que se han hecho a este respecto en 1975-76, en el marco de un proyecto de las Naciones Unidas, han dado resultados esperanzadores. La dificultad principal ha estribado en la concepción de los nudos de la estructura espacial. Tras la experiencia adquirida con este proyecto y con los desarrollos posteriores efectuados en Suecia, la sociedad Habitropic puede hoy en día difundir el Nudo de Estructura Espacial, en los países en vías de desarrollo para su venta o su producción bajo licencia. 